\title{
Major histocompatibility complex in Osteichthyes
}

\author{
Michał Stosik ${ }^{1}$, Beata Tokarz-Deptuła ${ }^{2}$, Wiesław Deptuła ${ }^{3}$ \\ ${ }^{1}$ Institute of Biological Sciences, University of Zielona Góra, 65-516 Zielona Góra, Poland \\ ${ }^{2}$ Institute of Biology, University of Szczecin, 70-453 Szczecin, Poland \\ ${ }^{3}$ Institute of Veterinary Medicine, Faculty of Biological and Veterinary Sciences, \\ Nicolaus Copernicus University in Torun, 87-100 Torun, Poland \\ m.stosik@outlook.com
}

Received: August 16, 2019 Accepted: March 6, 2020

\begin{abstract}
Based on analysis of available genome sequences, five gene lineages of MHC class I molecules (MHC I-U, -Z, -S, -L and -P) and one gene lineage of MHC class II molecules (MHC II-D) have been identified in Osteichthyes. In the latter lineage, three MHC II molecule sublineages have been identified (MHC II-A, -B and -E). As regards MHC class I molecules in Osteichthyes, it is important to take note of the fact that the lineages $U$ and $\mathrm{Z}$ in MHC I genes have been identified in almost all fish species examined so far. Phylogenetic studies into MHC II molecule genes of sublineages A and B suggest that they may be descended from the genes of the sublineage named A/B that have been identified in spotted gar (Lepisosteus oculatus). The sublineage E genes of MHC II molecules, which represent the group of non-polymorphic genes with poor expression in the tissues connected with the immune system, are present in primitive fish, i.e. in paddlefish, sturgeons and spotted gar (Lepisosteus oculatus), as well as in cyprinids (Cyprinidae), Atlantic salmon (Salmo salar), and rainbow trout (Oncorhynchus mykiss). Full elucidation of the details relating to the organisation and functioning of the particular components of the major histocompatibility complex in Osteichthyes can advance the understanding of the evolution of the MHC molecule genes and the immune mechanism.
\end{abstract}

Keywords: Osteichthyes, major histocompatibility complex.

\section{Introduction}

The major histocompatibility complex (MHC) in humans is a set of highly polymorphic genes coding for histocompatibility antigens which are the molecules MHC I and MHC II presenting antigens to T-lymphocytes, and of genes displaying limited polymorphism and coding for MHC III molecules which are also associated with immune response. It is important to point out, also with regard to the diversity of the MHC molecules, which may be classical or non-classical, that the ability to present antigens and the activation of $\mathrm{T}$ lymphocytes is linked to both the high polymorphism of $\mathrm{MHC}$ molecules and the level of their expression in cells. In humans, the genes of the major histocompatibility complex can be found on the short arm of chromosome 6 . The $H L A-A, H L A-B$, and $H L A-C$ (human leukocyte antigen-A, $-\mathrm{B},-\mathrm{C})$ genes that code for the classical MHC molecules (class Ia, MHC Ia) can be found in the MHC I region, in the telomere part of chromosome 6 . These molecules are highly polymorphic and play a key role in the presentation of proteins. The same part also contains the $H L A-E, H L A-F$, and $H L A-G$ genes as well as the $M I C A$ and $M I C B$ (MHC class I-related chain -A, -B) genes which code for the non-classical MHC I molecules (class Ib, MHC Ib). As opposed to the MHC Ia molecule, MHC I non-classical molecules display a significantly lesser degree of polymorphism, and their distribution in tissues is significantly more limited. The MHC II region, which is situated closer to the centromere, contains the $H L A-D P, H L A-D Q$ and $H L A-D R$ genes that condition the synthesis of the classical MHC II molecules (class IIa, MHC IIa). These are highly polymorphic, as MHC Ia also is, and play a major part in the protein presentation. In that region there are also the $H L A-D M$ and $H L A-D O$ genes which code for the non-classical MHC II (class $\mathrm{IIb}$, MHC IIb) molecules, i.e. the HLA-DM and HLA-DO molecules which are atypical and not very polymorphic, and their role in the antigen presentation is limited to participation in the exchange of the CLIP (class II-associated invariant chain) peptide for the antigen. The region of the genes encoding MHC class III 
molecules is situated between the MHC I region and the MHC II region. It encompasses the genes of the complement system components (proteins $\mathrm{C} 2$ and $\mathrm{C} 4$ ) and those of factor $\mathrm{B}$, as well as other genes, e.g. the genes encoding tumour necrosis factors (TNF) $\alpha$ and $\beta$ and a heat shock protein (HSP) 70. It should be noted, however, that the classical antigens of the major histocompatibility complex in humans, the MHC Ia and MHC IIa molecules, as well as some non-classical molecules of both the MHC antigen types take part, as key elements, in the development of adaptive immune response $(7,11,19,21,38)$.

In humans, MHC class I molecules can be found on the surfaces of nuclear cells, erythrocytes, and platelets. The molecules are composed of the heavy chain $\alpha$ that consists of domains $\alpha 1, \alpha 2$, and $\alpha 3$, and of a light chain linked by a non-covalent bond, i.e. the $\beta 2$ subunit called a microglobulin $(\beta 2 \mathrm{M})$. The external domains $\alpha 1$ and $\alpha 2$ of heavy chain $\alpha$, which are distinguished by high polymorphism, form an antigen-binding groove - a place where endogenous antigens originating from the cell's own peptides and the pathogens replicating inside the cell or viruses bind to each other. These molecules develop in the lumen of the endoplasmic reticulum (ER), where heavy chain $\alpha$ combines with $\beta 2 \mathrm{M}$. There, MHC I molecules, accompanied by tapasin that temporarily strains the antigen-binding groove and takes part in binding high affinity peptides, take the form of an immune complex - an antigen peptide - MHC I (p-MHC I). Once the p-MHC I complex has emerged onto the surface of the cell, it takes part in the presentation of antigens to CD8+ cytotoxic T lymphocytes (11, 19, 21, 38). Relatively less is known about the functions of the MHC Ib molecules coded for by the considerably less polymorphous genes $H L A-E, H L A-F$ and $H L A-G$ (19). The MIC A and MIC B molecules, which are functionally different from MHC Ia, are, on the other hand, considered products of the genes expressed on the neoplastic cell surface, and ligands for the C-type lectin receptor $\mathrm{NKG} 2 \mathrm{D}$ that is present on natural killer cells (NK) cells, T $\gamma \delta$ lymphocytes, $\mathrm{T} \alpha \beta \mathrm{CD} 8^{+}$lymphocytes, and macrophages. It is necessary to emphasise that the proteins from the family of C-type lectin receptors play an important role in the susceptibility of neoplastic cells to the activity of NK cells $(11,18)$.

In humans, the MHC II molecules which are present on the surface of the antigen-presenting cells (APCs), including in particular dendritic cells, B lymphocytes, and macrophages, are responsible for the presentation of the antigen to the CD4+ helper T lymphocytes in the form of a p-MHC II complex (19, 38). These molecules are composed of chains $\alpha$ and $\beta$, linked by a non-covalent bond. Each of the chains consists of two domains, respectively $\alpha 1$ and $\alpha 2$ and $\beta 1$ and $\beta 2$. The external domains of both chains, $\alpha 1$ and $\beta 1$, are characterised by high polymorphism and produce an antigen-binding site - the groove. MHC II molecules develop, akin to MHC I molecules, in the lumen of an endoplasmic reticulum where the $\alpha$ and $\beta$ chains combine to form a complex with an invariant chain (Ii-chain). In such a form, the molecules are eventually transported to late endosomal compartments. There, the Ii-chain is trimmed by cathepsins and, as a result, only the fragment called MHC class II-associated invariant chain peptide, CLIP, which functions as a substitute peptide, remains with the groove that binds the peptide of the MHC II molecule. In the subsequent development phases of the immune response, the substitute peptide is replaced by a peptide with higher affinity, that is, with an endosomal peptide from endogenous proteins or with a peptide of endocytic origin. This process involves the MHC IIb and HLA-DM molecules as protein replacement catalysts (a similar role is played by tapasin in the formation of the p-MHC I complex), whereby the role of the proteins is controlled by the HLA-DO molecule $(14,19,38)$.

In the past, the immune system in Osteichthyes has been perceived as a system that is functionally limited to innate immune mechanisms, although research into MHC molecule genes in these animals was undertaken as long ago as in the 1970s and covered, among other fish species, zebrafish (Danio rerio, synonym Brachydanio rerio), rainbow trout (Oncorhynchus mykiss), olive flounder (Paralichthys olivaceus), European bass (Dicentrarchus labrax), channel catfish (Ictalurus punctatus), and turbot (Scophthalmus maximus) (17). Based on analysis of available genome sequences, five gene lineages of MHC class I molecules (MHC I-U, -Z, $-\mathrm{S}$, -L, and -P) and one gene lineage of MHC class II molecules (MHC II-D) have been identified in Osteichthyes. In the latter lineage, three MHC II molecule sublineages have been identified (MHC II-A, $-B$, and $-\mathrm{E})$. The presence of molecules of the MHC I-U and $-Z$ lineages has been proven in, among other fish species, zebrafish, Atlantic salmon (Salmo salar), medaka (Oryzias latipes), Nile tilapia (Oreochromis niloticus), three-spined stickleback (Gasterosteus aculeatus), torafugu (Takifugu rubripes), spotted green pufferfish (Tetraodon nigroviridis), and Mexican tetra (Astyanax mexicanus). In contrast, all the MHC I and MHC II molecule lineages represented by different numbers of genes have only been found in Atlantic salmon (Table 1) $(5,11,13)$. Given the enormous diversity and the very high numbers of taxonomic units for fish classified into the superclass Osteichthyes, it is important to recognise the infraclass Teleostei (class Actinopterygii, subclass Neopterygii) as the most populous taxonomic group. In the investigation of the structure and the functions of the major histocompatibility complex, most attention has been paid to fish classified into Teleostei, and the fish about which most is known include representatives of the clades Otomorpha (synonym: Otocephala), e.g. zebrafish; Neoteleostei, e.g. medaka; and fish from the group Protacanthopterygii (superorder Protacanthopterygii), e.g. rainbow trout and Atlantic salmon $(2,40)$. It should be added that in Osteichthyes, the karyotype is not homogeneous, although in most species, it contains 
25 pairs of acrocentric chromosomes and between 48 and 52 chromosome arms. Salmonidae have between 96 and 104 chromosome arms, which is a result of the whole genome duplication (WGD) in the ancestor of this taxonomic group and is considered a modal value in Salmonidae, inter alia in rainbow trout. However, Atlantic salmon are characterised by a certain dissimilarity: their karyotype contains 12 pairs of large acrocentric chromosomes and 72-74 chromosome arms (31). The distribution of the genes of the major histocompatibility complex in Osteichthyes is also complicated and thus far more different from that in humans. In Atlantic salmon, they are on 15 chromosomes $(5,11,13)$ (Table 1$)$.

Table 1. MHC class I and II gene loci in Atlantic salmon $(5,13)$ (a) against the background of the relevant data for humans (b)

\begin{tabular}{|c|c|c|c|c|}
\hline \multicolumn{5}{|c|}{ (a) } \\
\hline Chr. & & $\begin{array}{c}{ }^{*} \text { MHC I genes in Salmo salar (Sasa) } \\
(\text { MhcSasa-U... or } Z, S, L, P \ldots)\end{array}$ & & $\begin{array}{c}{ }^{*} \text { MHC II genes in Salmo salar (Sasa) } \\
(\text { MhcSasa-D...) }\end{array}$ \\
\hline 2 & None & & & $D C B 1, D C A / D E A, D E B / D C B 2$ \\
\hline 5 & None & & & $D E A \psi, D E B \psi$ \\
\hline 7 & & $P A A \psi$ & None & \\
\hline 9 & & $S A A$ & None & \\
\hline 10 & & $L K A \psi$ & None & \\
\hline 11 & & $L C A, L C A \psi$ & None & \\
\hline 12 & & $L D A$ & & $D D A, D D B /{ }^{* *} D A A, D A B 1$ \\
\hline 13 & None & & & $D B B, D B A$ \\
\hline 14 & & $U D A 1, U C A 2 / U C A 1, U G A / Z B A b, Z C A b, Z D A b \psi$ & None & \\
\hline 20 & & $S A A \psi$ & None & \\
\hline 21 & & $L I A$ / UHA1, UHA2 & None & \\
\hline 22 & None & & & $D A B \psi$ \\
\hline 25 & & $L I A \psi / L L A \psi$ & None & \\
\hline 26 & & $L F A, L G A, L H A$ & None & \\
\hline 27 & & $U L A,{ }^{* *} U B A, Z A A a, Z B A a, Z C A a, Z D A a$ & None & \\
\hline \multicolumn{5}{|c|}{ (b) } \\
\hline Chr. & & MHC I genes in humans & & MHC II genes in humans \\
\hline 6 & & $\begin{array}{c}{ }^{* *} H L A-A, H L A-B, H L A-C \\
H L A-E, H L A-F, H L A-G, M I C A \text { and } M I C B\end{array}$ & & $\begin{array}{c}{ }^{* *} H L A-D P, H L A-D Q \text { and } H L A-D R \\
H L A-D M \text { and } H L A-D O \\
\end{array}$ \\
\hline
\end{tabular}

Chr. - chromosome no.; symbol ( / ) - divides genes with separate loci; ${ }^{*}$ - the constituents of the nomenclature of MHC class I and class II genes are listed in Tables 2 and $4 ; * *$ - genes of the classical MHC molecules

Table 2. Constituents of the nomenclature of MHC class I genes (table cells with grey underlay) in fish on the example of Atlantic salmon (11, 13)

\begin{tabular}{|c|c|c|c|c|c|c|c|}
\hline $\mathrm{MHC}$ & $\begin{array}{l}\text { Fish genus } \\
\text { and species } \\
\text { symbol }\end{array}$ & $\begin{array}{l}\text { MHC class I } \\
\text { gene } \\
\text { lineage } \\
\end{array}$ & $\begin{array}{l}\text { MHC class I } \\
\text { gene } \\
\text { sublineage }\end{array}$ & Locus & Subclass & Gene & Full name / symbol of gene \\
\hline \multirow{5}{*}{$M h c$} & \multirow{5}{*}{ Sasa } & $U$ & None & $\begin{array}{l}B \\
C \\
D \\
G \\
H \\
L\end{array}$ & \multirow{5}{*}{$A$ (for chain $\alpha$ ) } & $\begin{array}{l}U B A^{* *} \\
U C A 1^{* * *}, U C A 2 \\
U D A 1 \\
U G A \\
U H A 1, U H A 2 \\
U L A\end{array}$ & $\begin{array}{l}\text { MhcSasa-UBA } \\
\text { MhcSasa-UCA1, MhcSasa-UCA2 } \\
\text { MhcSasa-UDA1 } \\
\text { MhcSasa-UGA } \\
\text { MhcSasa-UHA1, MhcSasa-UHA2 } \\
\text { MhcSasa-ULA }\end{array}$ \\
\hline & & $Z$ & $Z 1^{*}$ & $\begin{array}{l}A \\
B \\
C \\
D\end{array}$ & & $\begin{array}{l}Z A A a \\
Z B A a, Z B A b \\
Z C A a, Z C A b \\
Z D A a, Z D A b \psi\end{array}$ & 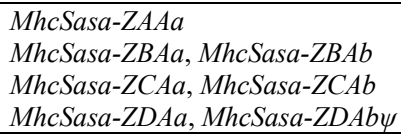 \\
\hline & & $S$ & None & $A$ & & $S A A, S A A \psi$ & 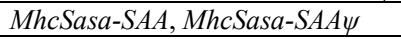 \\
\hline & & $L$ & None & $\begin{array}{l}C \\
D \\
F \\
G \\
H \\
I \\
K \\
L\end{array}$ & & 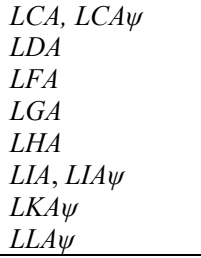 & 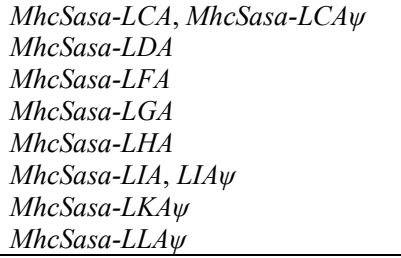 \\
\hline & & $P$ & None & $A$ & & $P A A \psi$ & 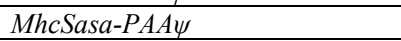 \\
\hline
\end{tabular}

$*$ - sublineage $Z 1$ with a typical sequence, isolated in, inter alia, Salmo salar; ** - a gene of an MHC Ia molecule; *** - locus no.; $\psi$ - pseudogenes 


\section{MHC class I molecules in Osteichthyes}

As previously mentioned, five lineages of $\mathrm{MHC}$ class I molecules, MHC I-U, -Z, -S, -L, and -P (13), have been identified in Osteichthyes based on phylogenetic grouping, and the gene nomenclature for $\mathrm{MHC}$ molecules, both for class I and class II has been introduced according to Klein et al. (20), as mentioned by Grimholt (11). A full name (symbol) of a gene should contain the following constituents: $M h c$, next, the first two letters of the generic and specific name of an animal/fish, e.g. Sasa from Salmo salar, plus other symbols. For genes of MHC I molecules, the first symbol, which indicates the class identification of the gene, is the letter $\mathrm{U}$ (from the Latin word uno). This letter has been first adopted to describe the genes identified in Atlantic salmon. Depending on the fish species in which the genes were subsequently identified, or on other details related to subsequently identified genes of the same class, other symbols are used. These are the letters $-\mathrm{Z},-\mathrm{S},-\mathrm{L}$, and $-\mathrm{P}$. The next symbol is the letter that represents the gene locus, while the third symbol, A (for chain $\alpha$ ), refers to the subclass (11) (Table 2).

Among the lineage $U$ genes in Osteichthyes, the genes of the classical (MHC Ia) and non-classical (MHC Ib) MHC molecules have only been identified in a few species. A gene of the classical MHC I molecule in Osteichthyes was first identified in Atlantic salmon and described in 1993. It was later named MhcSasa-UBA and evidence was found that it can occur in a number of versions - in the form of multiple alleles (11). The classical MHC I molecules have also been proven to occur in medaka (28), pompano (Trachinotus ovatus) (3), rainbow trout, as well as in pink salmon (Oncorhynchus gorbuscha) and in cyprinids (Cyprinidae) $(11,13)$. In medaka apart from the gene of the classical MHC I-UBA molecule (locus B), also another gene for the MHC Ia molecule has been found. It is identified as MHC I-UAA (locus A). These genes, except for the wide range of alleles, e.g. from 1 to 3 alleles of $U B A$ gene in pompano (Trachinotus ovatus), 44 alleles of the $U B A$ gene in Atlantic salmon, and 50 alleles of the $U B A$ gene in rainbow trout, distinguish themselves in expression in a variety of fish tissues (3, $11,13,27,28)$. The other genes of MHC I-U molecules in Salmonidae, i.e. UHA,UDA,UCA,UGA,ULA, as well as $U E A$ and $U F A$, have been classified into MHC Ib molecules with limited polymorphism. Also, there are additional duplicated loci of the genes of MHC Ia and MHC Ib molecules in Salmonidae that have developed in the process of duplication of the genome of vertebrates (WGD) $(11,23,33)$. The genes of MHC Ib molecules, $U D A$ and $U E A$ in medaka, just as the genes $U B A$ and $U A A$ of MHC Ia molecules, have been proven to occur in the MHC I region. In contrast, the other genes, UCA, UGA,UHA, and UIA, are scattered throughout other regions of the genome (27). Research on zebrafish has shown that the genes of MHC Ia molecules or of potentially classical MHC I molecules occur within six haplotypes $(\mathrm{A}-\mathrm{F})(26)$. The MHC Ia genes include $U D A, U E A$, and $U F A$ within haplotype A, and $U B A$ and $U J A$ within haplotypes $\mathrm{B}$ and $\mathrm{C}$, respectively. A likely possibility of being classified into the group of MHC Ia genes has been ascribed to the genes $U G A$ (haplotype D), $U H A$ (haplotype F), and $U I A$ (haplotype E) (26). The lineage $U$ gene diversity in Osteichthyes is, however, much greater than that presented above. Studies have found, for example, that in Atlantic cod (Gadus morhua) there are 42 polymorphic genes of the lineage $U$ per specimen, with absent MHC class II molecules in this species, whereas the Nile tilapia (Oreochromis niloticus) has been proven to have 45 genes of MHC I-U molecules, and the threespined stickleback (Gasterosteus aculeatus) has been described as having 29 genes in which, both in the cases of Nile tilapia and the three-spined stickleback (Gasterosteus aculeatus), as opposed to Atlantic cod, MHC II molecules are present $(13,35)$.

Separate genes of MHC class I molecules, characterised by sequences other than genes of $\mathrm{MHC}$ $\mathrm{I}-\mathrm{U}$ molecules and first identified in cyprinids, have been classified as lineage $\mathrm{Z}$ genes of MHC I molecules (MHC I-Z). Similar genes but with not the same sequences have been identified in the Mexican tetra and other species of Osteichthyes. This has led to adoption of a new division of the genes of MHC I-Z molecules, in which genes with a typical sequence were separated and classified into sublineage Z1. Such genes are present in, among other species, Atlantic salmon, zebrafish, medaka, threespined stickleback (Gasterosteus aculeatus), and Nile tilapia. Genes with an atypical sequence as in the Mexican tetra and as in carps (Cyprinus carpio) were classified into sublineages Z2 and Z3, respectively (11, 13). The species of Osteichthyes in question have been shown to have different numbers of genes of MHC I-Z molecules. For example, in the Mexican tetra, 18 genes were identified, including 10 sublineage $Z 1$ genes and eight sublineage $\mathrm{Z} 2$ genes, whereas ten genes of zebrafish were classified into sublineage Z1, and in the three-spined stickleback and Atlantic cod, one lineage Z1 gene was found. However, each of the above fish species expressed at least one sublineage $\mathrm{Zl}$ gene. Moreover, the fact that the sequences of the majority of the analysed sublineage $\mathrm{Z} 1$ genes are similar to the 37 amino acid residues forming hollows, or pockets $\mathrm{A}$ to $\mathrm{F}$ in the antigen-binding groove made up of domains $\alpha 1$ and $\alpha 2$ of the classical MHC I HLA-A2 molecules in humans appears to be particularly interesting, also from the evolutionary point of view. For the Atlantic salmon, zebrafish, medaka, three-spined stickleback, Nile tilapia, spotted green pufferfish, torafugu, and Amazon molly (Poecilia formosa), the degree of similarity of most residues was between $90 \%$ and $100 \%$. It may therefore be concluded that the MHC I-Z Z1 molecules identified in Osteichthyes have a common (the same or similar in all the fish species studied) ligand that has not been identified / determined to date $(11,13)$.

As regards MHC class I molecules of the $-\mathrm{S},-\mathrm{L},-\mathrm{P}$ lineages in Osteichthyes, it is supposed that they most 
likely do not bind antigens and their function remains unclear $(5,11,13)$. MHC I-S lineage genes have been recognised in the aju (synonyms sweetfish, Plecoglossus altivelis), Atlantic salmon, Mexican tetra, and channel catfish (Ictalurus punctatus) $(11,13)$. These molecules are characterised by the absence of the sequence of amino acid residues that forms the antigen-binding groove and are typical of the classical MHC I molecules. The short cytoplasmic part is another common feature of MHC I molecules of lineage S (11), making them similar to the HLA-G molecules in humans that display a low degree of polymorphism and, at the same time, a wide range of immunoregulatory properties $(10,11)$.

Genes of MHC I-L molecules have been found in, among other species, spotted gar (Lepisosteus oculatus) -2 genes, zebrafish -16 genes, Mexican tetra -2 genes, Atlantic salmon -10 genes, and Nile tilapia -1 gene $(8$, 11, 13). Loss of introns at some genes of MHC I-L molecules, to different extents in different fish species, is a peculiar property of theirs. The rainbow trout has been shown to have no introns separating the exons that code for domains $\alpha 1, \alpha 2$, and $\alpha 3$ in genes $L B A, L C A$, and $L D A$, as opposed to gene $L A A$ that has a complete set of introns. The Nile tilapia demonstrates a completely different picture of the $L A A$ gene structure with absent introns between domains $\alpha 1$ and $\alpha 2(6,13)$. Furthermore, as is the case with lineage $\mathrm{S}$ molecules, there are also no amino acid residues typical of peptide/ antigen-binding sites in the sequence of genes of MHC I-L molecules (11).

Different numbers of MHC I-P molecules have been found in spotted gar, Mexican tetra, Atlantic cod, spotted green pufferfish (Tetraodon nigroviridis), Atlantic salmon (Salmo salar), sablefish (Anoplopoma fimbria), European bass (Dicentrarchus labrax), as well as in cavefish and torafugu $(11,13)$. Most genes of MHC I-P molecules occur in torafugu (Takifugu rubripes), however, only 8 of the 24 genes or gene fragments concerned code for MHC I-P molecules that have domains $\alpha 1-\alpha 3$. Some of the genes of lineage $P$ MHC I molecules in Osteichthyes are classified as pseudogenes, as evidenced for the cavefish in which loci of one gene and probably one pseudogene were found, and for the Atlantic salmon in which the only lineage $\mathrm{P}$ MHC I gene is a pseudogene (13). These molecules do not have any sequences of peptide- or ligand-binding residues and are therefore classified as non-classical MHC I molecules. However, they are characterised, just as MHC I-UBA, -UEA, and-UIA molecules (27), by the presence of additional cysteine molecules within the structure of domain $\alpha 1$, in a location that enables them to form a bond between the $\beta$-sheet and $\alpha$-helix. This may affect the structure and elasticity of this area, and ultimately the ability to bind ligands (11). The role of these molecules still remains unclear, also in the light of the absence of MHC I genes of lineages -L, -S, and -P in certain fish species.

To sum up the data relating to MHC class I molecules in Osteichthyes, it should be underlined that lineages $U$ and $\mathrm{Z}$ of MHC I genes have been found in almost all of the fish species examined to date, even in the oldest fish in terms of phylogenetics, e.g. in lungfish (subclass: Dipnoi) (lineage Z), paddlefish (family: Polyodontidae) (lineage U), sturgeons (family: Acipenseridae) (lineages U, Z), and in spotted gar (family: Lepisosteidae) (lineages U, Z) (Table 3). It is also noticeable that the classical MHC I molecules are descended from the genes located in lineage $U$.

\section{MHC class II molecules in Osteichthyes}

Based on phylogenetic studies, MHC class II molecules in Osteichthyes have been included in lineage $\mathrm{D}$ and in three sublineages marked with letters A, B, and E. In view of the need to revisit the nomenclature of these molecules, Grimholt (11) suggested that sublineage A should be reserved for sequences grouping with the sequences of the $D A A-D A B$ genes of the classical MHC II molecules in Salmonidae and medaka, sublineage E should be reserved for sequences grouping with the sequences of the $D E A-D E B$ genes in Salmonidae, whereas sublineage B should be reserved for genes grouping with the sequences of the $D B A-D B B$, $D C A-D C B 1, D C A-D C B 2$, and $D D A-D D B$ genes in the Atlantic salmon and the $D E A-D E B, D D A-D D B 1$, and $D D A-D D B 2$ genes in the medaka. In the nomenclature of genes of MHC II molecules in a specific fish genus and species, e.g. MhcSasa (from Salmo salar), in the further place, the first letter, D, denotes a MHC class II molecule, the next letter denotes the locus of a gene within a gene sublineage, and the third letter refers to the subclass $-A$ for chain $\alpha$ and $B$ for chain $\beta$ (11) (Table 4).

There is evidence that MHC II molecule genes of sublineages A and B have most likely evolved from genes of molecules similar to the lineage A and B genes in spotted gar, described as sublineage $\mathrm{A} / \mathrm{B}$ genes. MHC II molecule genes, $D A A-D A B$, are the only genes of the classical MHC II molecules in Osteichthyes that cluster in sublineage $\mathrm{A}(5,11,13)$. These genes, $D A A-D A B$, which code for both chain $\alpha$ and chain $\beta$, have been proven to be present in Atlantic salmon, rainbow trout, and medaka. They are characterised by a high level of expression in, inter alia, the pronephros and spleen, and by high polymorphism and the ability to bind the CD4 receptor $(1,5,16)$. As was the case with the structure of the classical MHC II molecules in mammals, the structure of domains $\alpha 1$ and $\beta 1$ of DAA-DAB molecules in Osteichthyes has been proven to have highly conserved amino acid residues $\alpha$ N62 and $\alpha$ N69, as well as $\beta \mathrm{H} 81$ and $\beta \mathrm{N} 82$ as elements of the so-called conservative sequence that has a key and invariable function in the peptide-binding process $(5,11)$. The presence of $\beta S 144$ and $\beta E 162$ residues, which are of great significance in the CD4 protein-binding process and in the antigen presentation, is another important feature of these molecules (11). 
Table 3. Occurrence of MHC I and MHC II genes in selected species of Osteichthyes $(11,13)$

\begin{tabular}{|c|c|c|c|c|c|c|c|c|c|c|}
\hline \multirow{5}{*}{ Selected species of Osteichthyes } & \multicolumn{7}{|c|}{ MHC I } & \multicolumn{3}{|c|}{ MHC II } \\
\hline & \multicolumn{10}{|c|}{ Lineage } \\
\hline & $\mathrm{U}$ & & Z & & $\mathrm{S}$ & $\mathrm{L}$ & $\mathrm{P}$ & \multicolumn{3}{|c|}{$\mathrm{D}$} \\
\hline & \multicolumn{10}{|c|}{ Sublineage } \\
\hline & - & $\mathrm{Z1}$ & $\mathrm{Z} 2$ & $\mathrm{Z3}$ & - & - & - & $\mathrm{A}$ & $\mathrm{B}$ & $\mathrm{E}$ \\
\hline Lungfish (subclass Dipnoi) & - & & $x^{*}$ & & - & - & - & - & - & - \\
\hline Paddlefish (family Polyodontidae) & $\mathrm{x}$ & & - & & - & - & - & - & - & $\mathrm{x}$ \\
\hline Sturgeon (family Acipenseridae) & $\mathrm{x}$ & & $\mathrm{x}^{*}$ & & - & - & - & - & - & $\mathrm{x}$ \\
\hline Spotted gar (Lepisosteus oculatus) & $\mathrm{x}$ & & $\mathrm{x}^{*}$ & & 0 & $\mathrm{x}$ & $\mathrm{x}$ & \multicolumn{2}{|c|}{$x$} & $\mathrm{x}$ \\
\hline Zebrafish (Danio rerio) & $\mathrm{x}$ & $\mathrm{x}$ & - & - & 0 & $\mathrm{x}$ & 0 & $\mathrm{x}$ & $\mathrm{x}$ & 0 \\
\hline Carp (Cyprinus carpio) & $\mathrm{x}$ & $\mathrm{x}$ & - & $\mathrm{x}$ & - & - & - & $\mathrm{x}$ & - & $\mathrm{x}$ \\
\hline Mexican tetra (Astyanax mexicanus) & $\mathrm{x}$ & $\mathrm{x}$ & $\mathrm{x}$ & - & $\mathrm{x}$ & $\mathrm{x}$ & $\mathrm{x}$ & - & - & - \\
\hline Atlantic salmon (Salmo salar) & $\mathrm{x}$ & $\mathrm{x}$ & - & - & $\mathrm{x}$ & $\mathrm{x}$ & $\mathrm{x}$ & $\mathrm{x}$ & $\mathrm{x}$ & $\mathrm{x}$ \\
\hline Medaka (Oryzias latipes) & $\mathrm{x}$ & $\mathrm{x}$ & - & - & 0 & 0 & 0 & $\mathrm{x}$ & $\mathrm{x}$ & 0 \\
\hline Stickleback (Gasterosteus aculeatus) & $\mathrm{x}$ & $\mathrm{x}$ & - & - & 0 & 0 & 0 & $\mathrm{x}$ & $\mathrm{x}$ & 0 \\
\hline
\end{tabular}

* - lineage Z; symbol ( - ) - lack of sufficient data to deduce that MHC genes of a specific lineage or sublineage are present or absent; 0 - lack of MHC genes of a specific lineage or sublineage; $\mathrm{x}$ - occurrence of MHC genes of a specific lineage or sublineage

Table 4. Constituents of the nomenclature of MHC class II genes (table cells with grey underlay) in fish on the example of Salmo salar and Oryzias latipes

\begin{tabular}{|c|c|c|c|c|c|c|c|}
\hline MHC & $\begin{array}{l}\text { Fish genus } \\
\text { and species symbol }\end{array}$ & $\begin{array}{l}\text { MHC class II } \\
\text { gene lineage }\end{array}$ & $\begin{array}{l}\text { MHC class II } \\
\text { gene sublineage }\end{array}$ & Locus & Subclass & Gene & Full name / symbol of gene \\
\hline \multirow{9}{*}{ Mhc } & \multirow{9}{*}{$\begin{array}{l}\text { Sasa } \\
\text { (Salmo salar) } \\
\text { Orla } \\
\text { (Oryzias latipes) } \\
\text { or another }\end{array}$} & \multirow{9}{*}{$D$} & \multirow[t]{3}{*}{$A$} & $A$ & \multirow{9}{*}{$\begin{array}{l}A \text { (for chain } \alpha) \\
B(\text { for chain } \beta)\end{array}$} & ${ }^{*} D A A-D A B$ & $\begin{array}{l}\text { MhcOrla-DAA-DAB } \\
\text { MhcSasa-DAA-DAB }\end{array}$ \\
\hline & & & & $C$ & & ${ }^{* * *} D C A-D C B$ & MhcOrla-DCA-DCB \\
\hline & & & & $F$ & & ${ }^{{ }^{* * *} D F A-D F B}$ & MhcOrla-DFA-DFB \\
\hline & & & $E$ & $E$ & & ${ }^{* *} D E A-D E B$ & MhcSasa-DEA-DEB \\
\hline & & & \multirow{5}{*}{$B$} & $B$ & & $D B A-D B B$ & MhcSasa-DBA-DBB \\
\hline & & & & $C$ & & $D C A-D C B 1 / 2$ & $\begin{array}{l}\text { MhcSasa-DCA-DCB1 } \\
\text { MhcSasa-DCA-DCB2 }\end{array}$ \\
\hline & & & & $D$ & & $D D A-D D B$ & MhcSasa-DDA-DDB \\
\hline & & & & & & $D D A-D D B 1 / 2$ & $\begin{array}{l}\text { MhcOrla-DDA-DDB1 } \\
\text { MhcOrla-DDA-DDB2 }\end{array}$ \\
\hline & & & & $E$ & & ${ }^{* *} D E A-D E B$ & MhcOrla-DEA-DEB \\
\hline
\end{tabular}

* - genes of the classical MHC II molecule; ** - gene clustering based on the domain $\alpha 1$ sequence, according to Dijkstra et al. (5) and Grimholt (11), with preservation of sublineage $\mathrm{E}$ for sequences making up a cluster with $D E A-D E B$ in Salmo salar and with creation of sublineage B with sequences forming a cluster with $D E A-D E B$ in Oryzias latipes; *** - pairs of Oryzias latipes genes with limited expression and low polymorphism, clustering in sublineage A (5)

Research into the structure and polymorphism of the MHC IIa gene (Trov-MHC IIa) in the pompano (Trachinotus ovatus) (4), just as in Nile tilapia (30), Japanese flounder (Paralichthys olivaceus) (34), turbot (Scophthalmus maximus) (41), and Atlantic salmon (Salmo salar) (36), as well as studies on the structure of the MHC II $\alpha$ and $M H C I I \beta$ genes in pond loach (Misgurnus anguillicaudatus) (17) have shown that the genes contain four exons and three introns. It has been confirmed that the first exon codes for the LP (leader peptide) protein, the second and the third exons code for domains $\alpha 1$ and $\alpha 2$, respectively, and the fourth exon codes for the CP (connecting peptide) protein, the transmembrane region (TM) and the cytoplasmic domain (CT) (4). In pompano, 29 alleles of the TrovMHC II gene with high polymorphism have been identified. The similarity of the amino acid sequences between the Trov-MHC II $\alpha$ gene and the HLA II, DM $\alpha$-chain precursor (NCBI reference sequence: NP_006111.2) in humans and the MHC II $\alpha$ genes in other fish species is in a range between $27.6 \%$ and $78.6 \%$ (4). These studies have also demonstrated that the Trov$D A A^{*} 6401$ and Trov-DAA 6702 alleles are linked to fish immunity to infection with Vibrio harveyi, whereas the Trov-DAA*6304 and Trov-DAA*7301 alleles are, in contrast, connected with fish susceptibility to infection with these bacteria. Also studies on polymorphism of alleles and haplotypes in the Atlantic salmon (11) and Nile tilapia (9) indicate similar relationships between allele polymorphism and immunity to infectious and invasive diseases in Osteichthyes. As regards inaccuracies in the data relating to genes of the classical MHC II molecules in Osteichthyes, clarification and further research are needed for, inter alia, the determination of the number of loci of the $D A A$ and $D A B$ genes. Research to date has established, for example, the loci of $22 D A A$ alleles and $42 D A B$ alleles in the Atlantic salmon, and, respectively, 3 and 22 alleles in rainbow trout. As Grimholt (11) states, this is most likely due to different technical and scientific approaches to the 
problem. It has also to be noted that within sublineage A of MHC II molecule genes also non-polymorphic genes, $D C A-D C B$ and $D F A-D F B$, that have been identified in the medaka and recognised as non-classical, do cluster (Table 4). In zebrafish, 14 genes have been identified within this lineage, and in the Nile tilapia 33 genes (5, 32). This state of identification of the issue can suggest, as emphasised by Grimholt (11), that varying degrees of polymorphism is not a sufficient criterion for dissimilarity between the classical and the non-classical MHC class II molecules.

The MHC II molecule genes clustering in sublineage B also display, just as those identified in sublineage $\mathrm{E}$, properties of non-classical genes, i.e. poorly expressed polymorphism, low expression level and inability to bind the CD4 receptors (11). Among the genes grouping in sublineage $\mathrm{B}$ are inter alia $D 8.45 / D 8.46$ in zebrafish, $D B A-D B B, D C A-D C B 1 / 2$ and $D D A-D D B$ identified in Atlantic salmon, and $D D A-$ $D D B 1 / 2, D E A-D E B$ found in medaka (5) (Table 3). What is salient is the sequence similarity between the $D E A-D E B$ and $D D A-D D B$ genes in medaka and the $D C A-D C B$ and $D B A-D B B$ genes, respectively, in Atlantic salmon. It can also be noted that the $D E A-D E B$ genes in medaka and the $D E A-D E B$ genes in Atlantic salmon are not, contrary to appearances, orthologous genes, as pointed out by Grimholt (11). In the light of the studies by Dijkstra et al. (5), it is very likely that the mechanism to bind an antigen peptide in the antigenbinding groove of the classical MHC II molecules in Osteichthyes is different from that in humans, especially in the absence of the non-classical MHC II molecules of sublineage B in some fish species. That is why a number of properties of the non-classical MHC II molecules in fish originating from sublineage B genes are in need of further investigation. It is necessary to establish the role and function of these molecules in interaction with the classical MHC molecules, particularly in the light of the clearly defined properties of similar molecules in humans, i.e. HLA-DM and HLA-DO $(5,11)$.

MHC II molecule genes of sublineage E occur in the phylogenetically oldest fish, the paddlefish (family: Polyodontidae), sturgeons (family: Acipenseridae), and in spotted gar. They have also been proven to be present in cyprinids (Cyprinidae), the Atlantic salmon, and rainbow trout $(5,11,29)$. MHC II genes of sublineage $\mathrm{E}$ in Osteichthyes are described on the basis of the properties of the MhcSasa-DEA and MhcSasa-DEB genes, identified in the Atlantic salmon on chromosome 2 (a duplicated form containing the $D E A \psi$ and $D E B \psi$ pseudogenes occurs in these fish on chromosome 5). These are non-polymorphic genes with poor expression in tissues connected with the immune system, such as the anterior kidney or spleen, and their role is not defined yet $(5,11)$.

As regards $\mathrm{MHC}$ class II molecules in Osteichthyes, it is important to emphasise that genes of the MHC IIa molecules occur within sublineage A, independently of the MHC IIb molecules with limited expression and low polymorphism, which are also present within this sublineage and which can play a role similar to that of the HLA-DO molecules in humans (5). Phylogenetic studies into MHC II molecule genes of sublineages A and B suggest that they may be descended from the genes of the sublineage named $\mathrm{A} / \mathrm{B}$ that have been identified in spotted gar (Lepisosteus oculatus) (11). Furthermore, it is remarkable that MHC II molecule genes of sublineage E occur in primitive fish, that is, in paddlefish (family: Polyodontidae), sturgeons (family: Acipenseridae), and spotted gar (family: Lepisosteidae) $(5,11,29)$.

\section{MHC molecules in Osteichthyes in the context of evolution}

A study on the MHC I haplotype variability in the Atlantic salmon, using the genome transcriptome and resources has shown limited levels of polymorphism of genes of the molecules that are functionally related to the antigen processing and to MHC Ia molecule genes (12). Also in that study, inhibited activity of other genes, duplicated in the second process of duplication of the genome of vertebrates (WGD) and involved in the assembly of MHC I and in the processing of the antigen, also in cyprinids and Salmonidae, could be observed. Studies conducted by Grimholt (12) show that the elimination of the haplotype contents in homologous regions of $\mathrm{MHC} \mathrm{Ia}$ is a result of the Osteichthyes genome duplication (TGD - teleost whole genome duplication) and of the duplication of the Atlantic salmon genome (SGD, salmonid whole genome duplication). This may have triggered the development of alternative mechanisms for the development of MHC I molecules and the processing of the antigen $(5,11-13)$. The MHC I regions identified in Osteichthyes, also the duplicated regions, have genes that are also shared by humans (Table 5). Research has shown that among the most important genes involved in the antigen binding and presentation in the Atlantic salmon, medaka, and zebrafish are also the TAPBP protein coding gene (TAPassociated glycoprotein, tapasin), TAP2 (antigen peptide transporter 2), as well as genes of immunoproteasome subunits, i.e. PSMB8 (proteasome subunit $\beta$ 8), PSMB9 (proteasome subunit $\beta$ 9), and PSMB10 (proteasome subunit $\beta$ 10) $(11,26,33,37)$. It should be emphasised that, as studies by Lital et al. (22) show, the constituents of the peptide loading complex (PLC) in rainbow trout are similar to those occurring in mammals but are enriched by a tapasin variant with weight of $20 \mathrm{kDa}$, which probably favours another peptide-binding mechanism.

As regards the loci of MHC II molecule genes in Osteichthyes, it is to be concluded that they are scattered and can hardly be defined as syntenic. The scattering of the genes is interpreted as a likely result of the translocation of these genes from the primary MHC region to different genome sites in different fish species. An example of the occurrence of genes of the MHC I and MHC II molecules in one common region is the gene distribution in the spotted gar. 
Table 5. Genes from selected MHC regions, identified in humans and fish $(5,13)$

\begin{tabular}{|c|c|c|c|c|c|c|c|}
\hline \multicolumn{2}{|c|}{ Humans } & \multicolumn{2}{|c|}{ Spotted gar } & \multicolumn{2}{|c|}{ Atlantic salmon } & \multicolumn{2}{|c|}{ Shared genes** } \\
\hline MHC I & MHC II & MHC I & MHC II & MHC I & MHC II & MHC I & $\mathrm{MHC} \mathrm{II}^{* * *}$ \\
\hline$H L A-G$ & $H L A-D R \alpha$ & $U(3$ loci $)$ & $E \alpha(2$ loci $)$ & $U^{*}$ & $E \alpha$ & $P S M B 8$ & $P B X 2$ \\
\hline$H L A-A$ & $H L A-D R \beta$ & $P(3$ loci $)$ & $E \beta(2$ loci $)$ & & $E \beta$ & $T U B B$ & TAP1 \\
\hline$H L A-E$ & $H L A-D Q \alpha$ & $L(2$ loci $)$ & $A / B \alpha$ & & & FLOT1 & $R G L 2$ \\
\hline$H L A-C$ & $H L A-D Q \beta$ & u.s. & $A / B \beta$ & & & TCF19 & PHF1 \\
\hline$H L A-B$ & $H L A-D P \alpha$ & & u.s. $\alpha$ & & & $T A P 2$ & $B R D 2$ \\
\hline & $H L A-D P \beta$ & & & & & PSMB9 & SYNGAP-like \\
\hline & $H L A-D M \alpha$ & & & & & $B R D 2$ & \\
\hline & $H L A-D M \beta$ & & & & & TAPBP & \\
\hline & 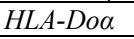 & & & & & $R X R B$ & \\
\hline & $H L A-D o \beta$ & & & & & $H S D 17 B 8$ & \\
\hline & & & & & & PSMB10 & \\
\hline
\end{tabular}

u.s. - undefined sequence; * - syntenic gene; ** - selected genes shared by humans (MHC region sized $\sim 4 \mathrm{Mb})$ and Salmo salar (MHC I and MHC II), as well as by Danio rerio and Oryzias latipes (MHC I); PSMB8-protein-coding gene, proteasome subunit $\beta$ type- $8 ; T U B B$ - protein-coding gene, tubulin $\beta$-chain; FLOT1 - protein-coding gene, flotillin-1; TCF19 - protein-coding gene, transcription factor 19; TAP2 - protein-coding gene, antigen peptide transporter 2; PSMB 9 - protein-coding gene, proteasome subunit $\beta$ type-9; BRD2 - protein-coding gene, bromodomain-containing protein 2; TAPBP - protein-coding gene, TAP-associated glycoprotein, also known as tapasin; $R X R B$ - gene, retinoid X reflex point $\beta$ (RXR- $\beta$ ); HSD17B8 - enzyme, oestradiol $17 \beta$-dehydrogenase 8; $P S M B 10$ - protein-coding gene, proteasome subunit $\beta$ type-10; $P B X 2$ - protein-coding gene, pre-B-cell leukaemia transcription factor $2 ; T A P 1$ - protein-coding gene, transporter associated with antigen processing 1 ; RGL2 - proteincoding gene, ral guanine nucleotide dissociation stimulator-like 2; $P H F 1$ - protein-coding gene, PHD finger protein 1; SYNGAP-like - Ras GTPase-activating protein SynGap-like; *** - genes occurring within sublineage E in Salmonidae

A partial picture of the primeval $\mathrm{MHC}$ region can also be seen in Salmonidae within sublineage $\mathrm{E}$ of the genes of the MHC class II molecules. In the Atlantic salmon on chromosome 2, there are loci of MHC II molecule genes and of other genes, such as BRD2, TAP1, PBX2, RGL2, PHF1, and SYNGAP-like (Table 5), while on chromosome 5 there is a duplicated region. However, in the rainbow trout, this region appears to be orthologous. Sublineage E of MHC II molecule genes in Salmonidae is considered the primeval MHC II region in Osteichthyes $(5,11,29)$. According to Grimholt $(11)$, the absence of some lineages or sublineages in certain species of Osteichthyes can be understood as functional limitation but, on the other hand, it is perhaps replaced with another mechanism that has evolved and may be able to bind or present the antigen. Examples could include the absence of genes of MHC class II $\alpha$ and II $\beta$ molecules and the inability to present antigens to CD4 T lymphocytes in Atlantic cod, and in all fish classified into the order Gadiformes from the class Actinopterygii (25), and broadnosed pipefish (Syngnathus typhle, class: Actinopterygii, order: Syngnathiformes, family: Syngnathidae $)(15,24,25,35,39)$. The seahorse (Hippocampus erectus, class: Actinopterygii, order: Syngnathiformes), which stands out with, among other things, a single copy of the MHC II $\alpha$ and II $\beta$ gene and an absent spleen or gut-associated lymphoid tissue, is a fish species that is particularly interesting in the context of immune response mechanisms and their evolution (24). The loss of molecules of the MHC II pathway in the fish species mentioned above was most probably due to independent and relatively recent events in terms of evolution (24). This is evidenced by the fact of the absolute absence of MHC II genes (sublineages A, $\mathrm{B}$, and E) in broadnosed pipefish (Syngnathus typhle) and in Atlantic cod, with these genes being present in the closely related big-belly seahorse (Hippocampus abdominalis) (39). These facts may be indicative of completely different organisation and functional efficiency of the mechanisms associated with MHC molecules in different species of Osteichthyes, especially in Atlantic cod. The facts may also have an influence on the understanding of the evolution of MHC molecule genes and other immune mechanisms (13, 24, 39). Given the immune mechanism imperfection related to MHC molecules in certain fish species, which is presented as a natural immune deficit, the compensatory role of innate immune mechanisms that are also conditioned by anatomical and physiological barriers $(24,39)$ is even more especially pointed out.

Conflict of Interests Statement: The authors declare that there is no conflict of interests regarding the publication of this article.

Financial Disclosure Statement: The article was financed by Institute of Veterinary Medicine, Faculty of Biological and Veterinary Sciences, Nicolaus Copernicus University in Toruń.

Animal Rights Statement: None required.

\section{References}

1. Bannai H.P., Nonaka M.: Comprehensive analysis of medaka major histocompatibility complex (MHC) class II genes: Implications for evolution in teleosts. Immunogenetics 2013, 65, 883-895.

2. Betancur-R.R., Wiley E.O., Arratia G., Acero A., Bailly N., Miya M., Lecointre G., Ortí G.: Phylogenetic classification of bony fishes. BMC Evolut Biol 2017, 17, 162, doi: 10.1186/s12862-017-0958-3.

3. Cao Z., He M., Chen X., Wang S., Cai Y., Xie Z., Sun Y., Zhou Y.: Identification, polymorphism and expression of MHC 
class I $\alpha$ in golden pompano, Trachinotus ovatus. Fish Shellfish Immunol 2017, 67, 55-65.

4. Cao Z., Wanga L., Xianga Y., Liua X., Tud Z., Suna Y., Zhou Y.: MHC class II $\alpha$ poly(40morphism and its association with resistance/susceptibility to Vibrio harveyi in golden pompano (Trachinotus ovatus). Fish Shellfish Immunol 2018, 80, 302-310, doi: 10.1016/j.fsi.2018.06.020.

5. Dijkstra J.M., Grimholt U., Leong J., Koop B.F., Hashimoto K.: Comprehensive analysis of MHC class II genes in teleost fish genomes reveals dispensability of the peptide-loading DM system in a large part of vertebrates. BMC Evolut Biol 2013, 13, 260

6. Dijkstra J.M., Katagiri T., Hosomichi K., Yanagiya K., Inoko H., Ototake M., Aoki T., Hashimoto K., Shiina T.: A third broad lineage of major histocompatibility complex (MHC) class I in teleost fish; MHC class II linkage and processed genes. Immunogenetics 2007, 59, 305-321.

7. Dirscherl H., McConnell S.C., Yoder J.A., de Jong J.L.O.: The MHC class I genes of zebrafish. Dev Comp Immunol 2014, 46, 11-23, doi: 0.1016/j.dci.2014.02.018.

8. Dirscherl H., Yoder J.A.: Characterization of the $\mathrm{Z}$ lineage major histocompatability complex class I genes in zebrafish. Immunogenetics 2014, 66, 185-198.

9. El-Magd M.A., El-Said K.S., El-Semlawy A.A., Tanekhy M., Afifi M., Mohamed T.M.: Association of MHC IIA polymorphisms with disease resistance in Aeromonas hydrophilachallenged Nile tilapia. Dev Comp Immunol 2019, 96, 126-134, doi: 10.1016/j.dci.2019.03.002.

10. Foroni I., Couto A.R., Bettencourt B.F., Santos M., Lima M., Bruges-Armas J.: HLA-E, HLA-F, and HLA-G - the non-classical side of the MHC cluster. In: HLA and Associated Important Diseases, Edited by Yongzhi Xi, In Tech, Rijeka, 2014, doi: $10.5772 / 57022$

11. Grimholt U.: MHC and evolution in teleosts. Biology 2016, 5, 6, doi: 10.3390/biology5010006.

12. Grimholt U.: Whole genome duplications have provided teleosts with many roads to peptide loaded MHC class I molecules. BMC Evolut Biol 2018, 18, 25, doi: 10.1186/s12862-018-1138-9.

13. Grimholt U., Tsukamoto K., Azuma T., Leong J., Koop B.F., Dijkstra J.M.: A comprehensive analysis of teleost MHC class I sequences. BMC Evolut Biol 2015, 15, 32, doi: 10.1186/s12862015-0309-1.

14. Guce A.I., Mortimer S.E., Yoon T., Painter C.A., Jiang W., Mellins E.D., Stern L.J.: HLA-DO acts as a substrate mimic to inhibit HLA-DM by a competitive mechanism. Nat Struct Mol Biol 2013, 20, 90-98, doi: 10.1038/nsmb.2460.

15. Haase D., Roth O., Kalbe M., Schmiedeskamp G., Scharsack J.P., Rosenstiel P., Reusch T.B.H.: Absence of major histocompatibility complex class II mediated immunity in pipefish, Syngnathus typhle: evidence from deep transcriptome sequencing. Biol Lett 2013, 9, 44, doi: 10.1098/rsbl.2013.0044.

16. Harstad H., Lukacs M.F., Bakke H.G., Grimholt U.: Multiple expressed MHC class II loci in salmonids; details of one nonclassical region in Atlantic salmon (Salmo salar). BMC genom 2008, 9, 193

17. Huang Z., Yu Y., Dong S., Yin Y., Wang Q., Yu W., Luo Y., Xu J., Zhang L., Yu Y., Ai T., Xu Z.: Major histocompatibility complex class IIA and IIB genes of loach (Misgurnus anguillicaudatus): molecular cloning and expression analysis in response to bacterial and parasitic challenge. Aquaculture 2019, 500, 359-369.

18. Jinushi M., Takehara T., Tatsumi T., Kanto T., Groh V., Spies T., Kimura R., Miyagi T., Mochizuki K., Sasaki Y., Hayashi N.: Expression and role of MICA and MICB in human hepatocellular carcinomas and their regulation by retinoic acid. Int $\mathrm{J}$ Cancer 2003, 104, 354-361.

19. Kelly A., Trowsdale J.: Introduction: MHC/KIR and governance of specificity. Immunogenetics 2017, 69, 481-488, doi: 10.1007/ s00251-017-0986-6.

20. Klein J., Bontrop R.E., Dawkins R.L., Erlich H.A., Gyllensten U.B., Heise E.R., Jones P.P., Parham P., Wakeland E.K., Watkins
D.I.: Nomenclature for the major histocompatibility complexes of different species: a proposal. Immunogenetics 1990, 31, 217-219.

21. Klimkiewicz-Wojciechowska G., Lech-Marańda E.: The role of human leukocyte antigen $\mathrm{G}$ in immunological mechanisms and its clinical implication. Hematologia 2012, 3, 327-342.

22. Lital S., Nguyen T.K.V., Niels C.B., Brian D.: Tapasin's protein interactions in the rainbow trout peptide-loading complex. Dev Comp Immunol 2018, 81, 262-270, doi: 10.1016/j.dci.2017. 12.015 .

23. Lukacs M.F., Harstad H., Bakke H.G., Beetz-Sargent M., McKinnel L., Lubieniecki K.P., Koop B.F., Grimholt U.: Comprehensive analysis of MHC class I genes from the U-, S-, and Z-lineages in Atlantic salmon. BMC Genom 2010, 11, 154

24. Luo W., Wang X., Qu H., Qin G., Zhang H., Lin Q.: Genomic structure and expression pattern of MHC II $\alpha$ and II $\beta$ genes reveal an unusual immune trait in lined seahorse Hippocampus erectus. Fish Shellfish Immunol 2016, 58, 521-529, doi: 10.1016/ j.fsi.2016.09.057.

25. Malmstrøm M., Matschiner M., Tørresen O.K., Star B., Snipen L.G., Hansen T.F., Baalsrud H.T., Nederbragt A.J., Hanel R., Salzburger W., Stenseth N.C., Jakobsen K.S., Jentoft S.: Evolution of the immune system influences speciation rates in teleost fishes. Nature Genet 2016, 48, 1204-1210.

26. McConnell S.C., Restaino A.C., de Jong J.L.: Multiple divergent haplotypes express completely distinct sets of class I MHC genes in zebrafish. Immunogenetics 2014, 66, 199-213.

27. Nonaka M.I., Aizawa K., Mitani H., Bannai H.P., Nonaka M.: Retained orthologous relationships of the MHC class I genes during euteleost evolution. Mol Biol Evol 2011, 28, 3099-3112.

28. Nonaka M.I., Nonaka M.: Evolutionary analysis of two classical MHC class I loci of the medaka fish, Oryzias latipes: haplotypespecific genomic diversity, locus-specific polymorphisms, and interlocus homogenization. Immunogenetics 2010, 62, 319-332.

29. Palti Y., Rodriguez M.F., Gahr S.A., Hansen J.D.: Evolutionary history of the ABCB2 genomic region in teleosts. Dev Comp Immunol 2007, 31, 483-498.

30. Pang J.C., Gao F.Y., Lu M.X., Ye X., Zhu H.P., Ke X.L.: Major histocompatibility complex class IIa and IIb genes of nile tilapia Oreochromis niloticus: genomic structure, molecular polymorphism, and expression patterns. Fish Shellfish Immunol 2013, 34, 486-496.

31. Phillips R.B., Keatley K.A., Morasch M.R., Ventura A.B., Lubieniecki K.P., Koop B.F., Danzmann R.G., Davidson W.S.: Assignment of Atlantic salmon (Salmo salar) linkage groups to specific chromosomes: conservation of large syntenic blocks corresponding to whole chromosome arms in rainbow trout (Oncorhynchus mykiss). BMC Genet 2009, 10, 46, doi: 10.1186/1471-2156-10-46.

32. Sato A., Dongak R., Hao L., Shintani S., Sato T.: Organization of Mhc class II A and B genes in the tilapiine fish Oreochromis. Immunogenetics 2012, 64, 679-690.

33. Shiina T., Dijkstra J.M., Shimizu S., Watanabe A., Yanagiya K., Kiryu I., Fujiwara A., Nishida-Umehara C., Kaba Y., Hirono I., Yoshiura Y., Aoki T., Inoko H., Kulski J.K., Ototake M.: Interchromosomal duplication of major histocompatibility complex class I regions in rainbow trout (Oncorhynchus mykiss), a species with a presumably recent tetraploid ancestry. Immunogenetics 2005, 56, 878-893.

34. Srisapoome P., Ohira T., Hirono I., Aoki T.: Cloning, characterization, and expression of cDNA containing major histocompatibility complex class I, II $\alpha$, and II $\beta$ genes of Japanese flounder Paralichthys olivaceus. Fish Sci 2004, 70, 264-276.

35. Star B., Nederbragt A.J., Jentoft S., Grimholt U., Malmstrom M., Gregers T.F., Rounge T.B., Paulsen J., Solbakken M.H., Sharma A., Wetten O.F., Lanzén A., Winer R., Knight J., Vogel J-H., Aken B., Andersen Ø., Lagesen K., Tooming-Klunderud A., Edvardsen R.B., Kirubakaran T.G., Espelund M., Nepal C., Previti C., Karlsen B.O., Moum T., Skage M., Berg P.R., Gjøen T., Kuhl H., Thorsen J., Malde K., Reinhardt R., Du L., Johansen S.D., Searle S., Lien S., Nilsen F., Jonassen I., Omholt S.W., Stenseth N.C., Jakobsen K.S.: The genome 
sequence of Atlantic cod reveals a unique immune system. Nature 2011, 477, 207-210.

36. Stet R.J., de Vries B., Mudde K., Hermsen T., van Heerwaarden J., Shum B.P., Grimholt U.: Unique haplotypes of co-segregating major histocompatibility class II A and class II B alleles in + (Salmo salar) give rise to diverse class II genotypes. Immunogenetics 2002, 54, 320-331.

37. Tsukamoto K., Hayashi S., Matsuo M., Nonaka M., Kondo M., Shima M.I., Asakawa S., Shimizu N., Nonaka M.: Unprecedented intraspecific diversity of the MHC class I region of a teleost medaka, Oryzias latipes. Immunogenetics 2005, 57, 420-431.

38. Wieczorek M., Abualrous E.T., Sticht J., Álvaro-Benito M., Stolzenberg S., Noé F., Freund C.: Major histocompatibility complex (MHC) class I and MHC class II proteins: conformational plasticity in antigen presentation. Front Immuno 2017, 8, 292, doi: 10.3389/fimmu.2017.00292.

39. Wilson A.B.: MHC and adaptive immunity in teleost fishes. Immunogenetics 2017, 69, 521-528, doi: 10.1007/s00251-0171009-3.

40. Yamaguchi T., Dijkstra J.M.: Major histocompatibility complex (MHC) genes and disease resistance in fish. Preprints 2019, doi: 10.20944/preprints201902.0179.v1.

41. Zhang Y.X., Chen S.L.: Molecular identification, polymorphism and expression analysis of major histocompatibility complex class II A and B genes of turbot (Scophthalmus maximus). Mar Biotechnol 2006, 8, 611-623. 